تخمين دماى سطح زمين بخش مركزى استان اصفهان از دادههاى حرارتى لندست ^ با استفاده از الخوريتم ينجره مجزا

مليحه السادات مدنيان "*، عليرضا سفيانيان'، سعيد سلطانى كويائى'، سعيد يورمنافى' و مهدى مومنى' (تاريخ دريافت: |T |

جكيده دماى سطح زمين (LST) يكى از مهم ترين منابع اطلاعاتى در مطالعه فرايندهايى نظير تبخير و تعرق، توسعه شاخص هاى متعدد، مـدلســازى

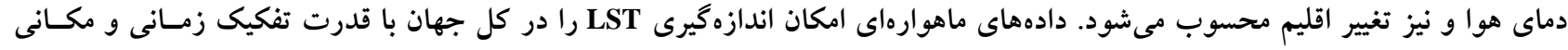

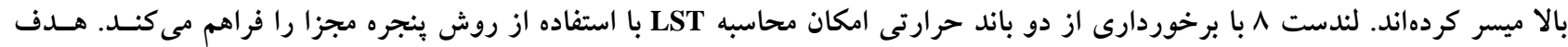

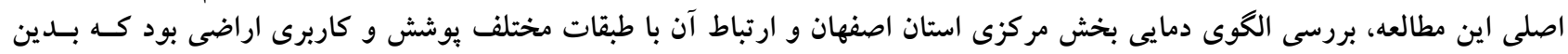

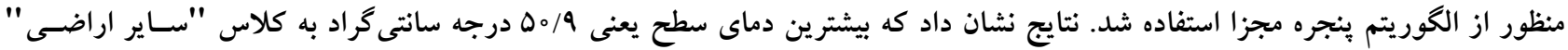

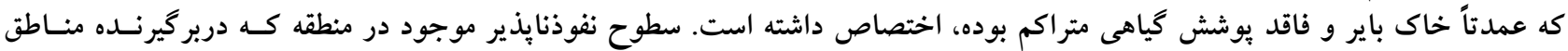

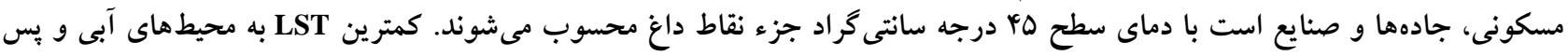

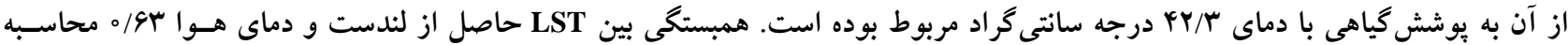

وازههاى كليدى: دماى سطح زمين، الكوريتم ينجره مجزا، لندست ^، بخش مركزى استان اصفهان

I. كروه محيط زيست، دانشكده منابع طبيعى، دانشگاه صنعتى اصفهان

r. كروه مرتع و آبخيزدارى، دانشكده منابع طبيعى، دانشكاه صنعتى اصفهان r. گروه مهندسى نقشهبردارى، دانشكده عمران و حمل و نقل، دانشخاه اصفهان madanian.ma@yahoo.com : مسئول مكاتبات: 
اندازهكيرى LST در اختيار قرار مىدهند. اين دادهها براى دورههـاى

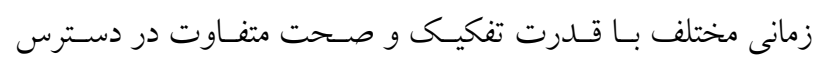

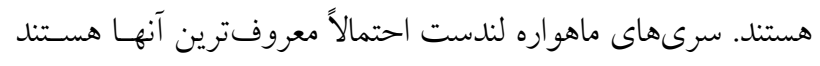

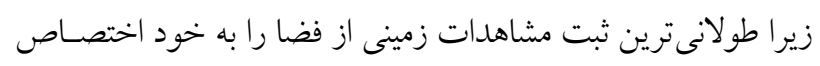

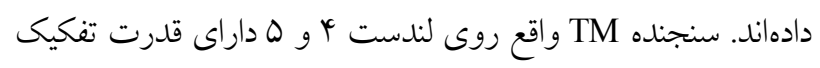

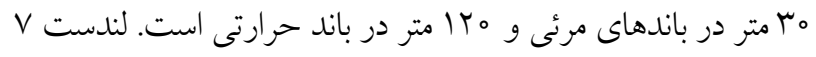

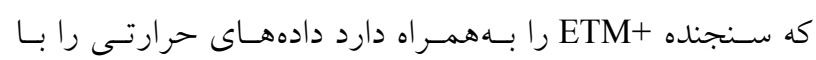

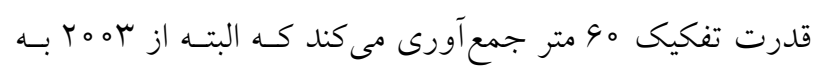

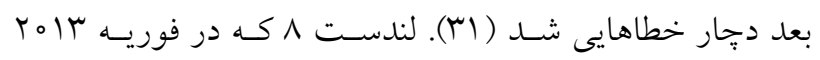
يرتاب شـد، دو سـنجنده Operational Land Imager) OLI) و TIRS را حمـل مسىكنـد (Thermal Infrared Sensor) TIRS

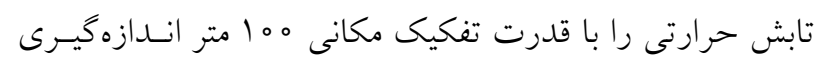
كرده و داراى دو باند مادون قرمز است (بT).

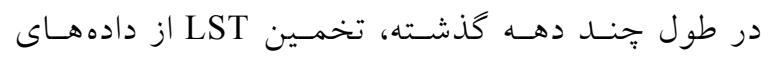

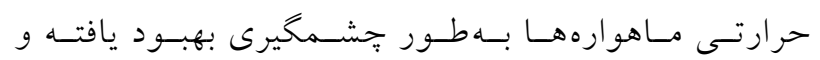

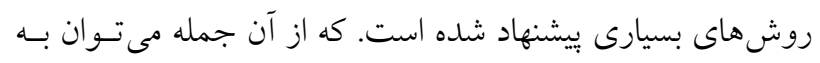

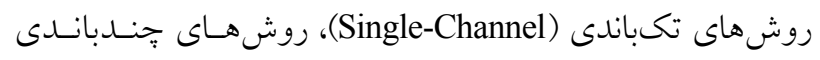

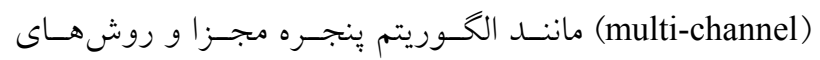

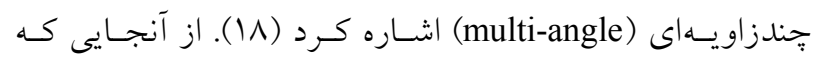

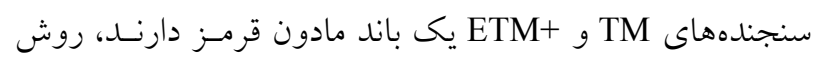

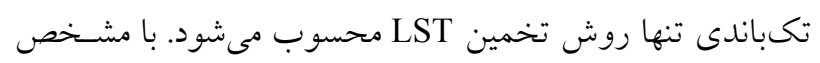

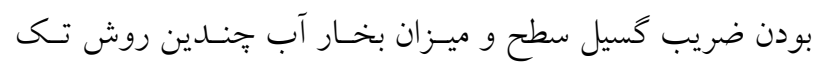

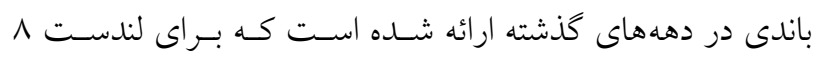

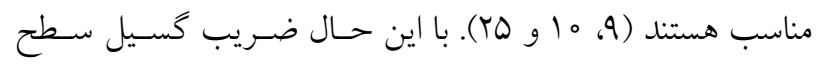
بهندرت معلوم است و عدم اطمينان يكى درصد در ايسن يـارامتر

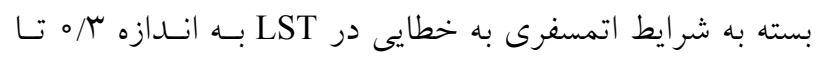

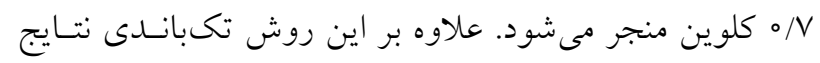

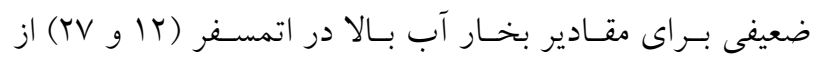

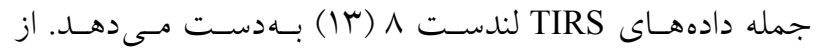
آنجايى كه TIRS داراى دو باند مادون قرمز است روش ينجـره

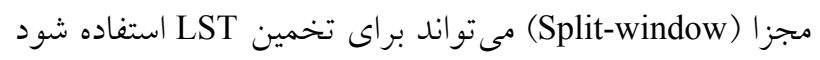

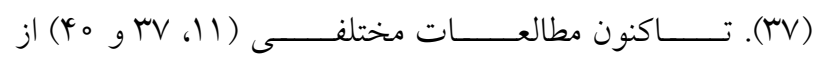

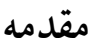

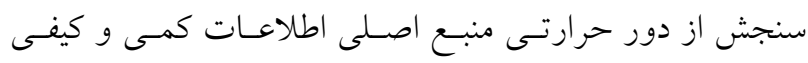

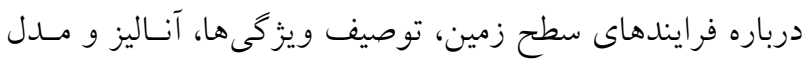

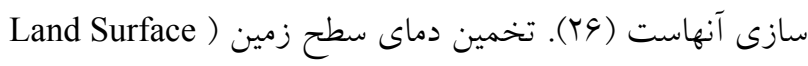
(Temperature

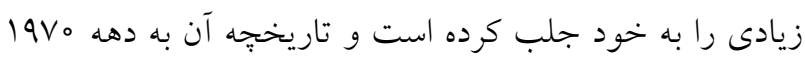

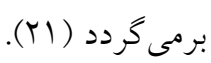

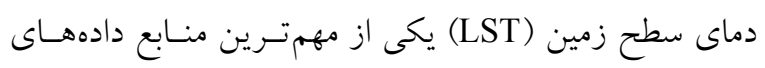

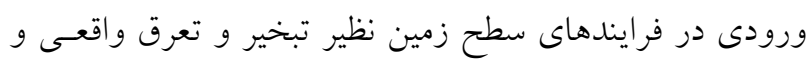

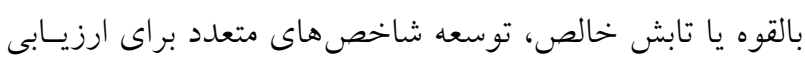

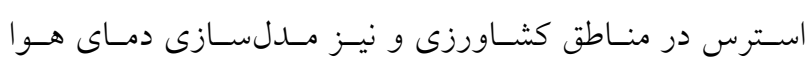

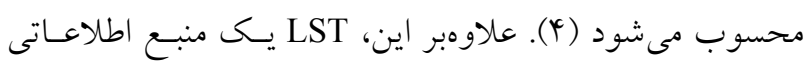
براى توليد متغير اقليمى ضرورى توسط سيستم مشـاهده اقلسيم

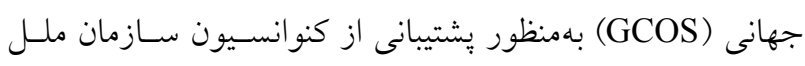

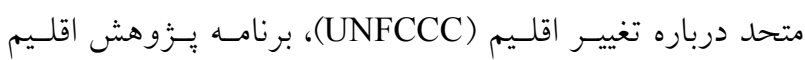

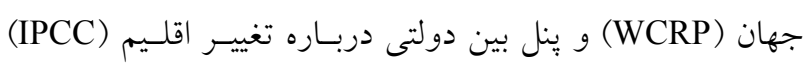
است (V و با وجود اينكه اندازهيرى هاى هواشناسى اطلاعـات دقيقى درباره دماى هوا از نظر زمانى فراهم مى كنند امـا در منـاطقى از

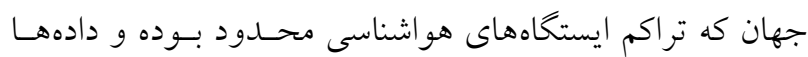

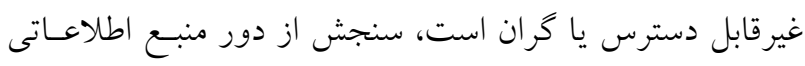

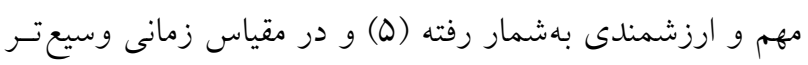

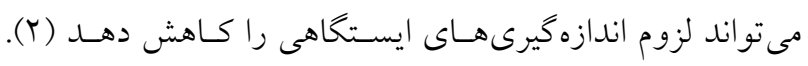

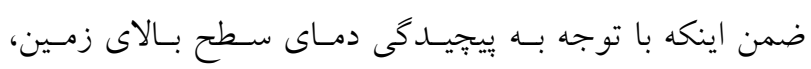

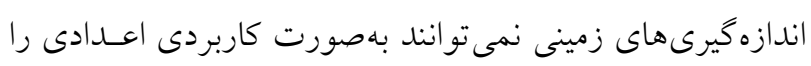

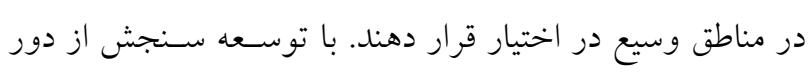

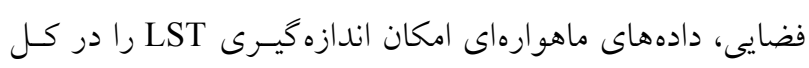

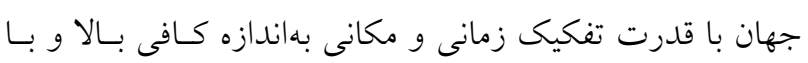

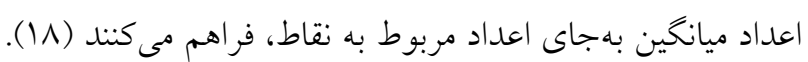

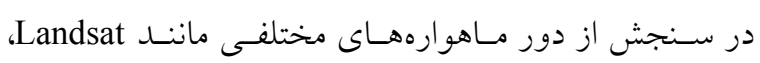
Aqua ،NOAA قرمز حرارتى وجود دارند كه مجموعه دادههاى سودمندى را بـراى 


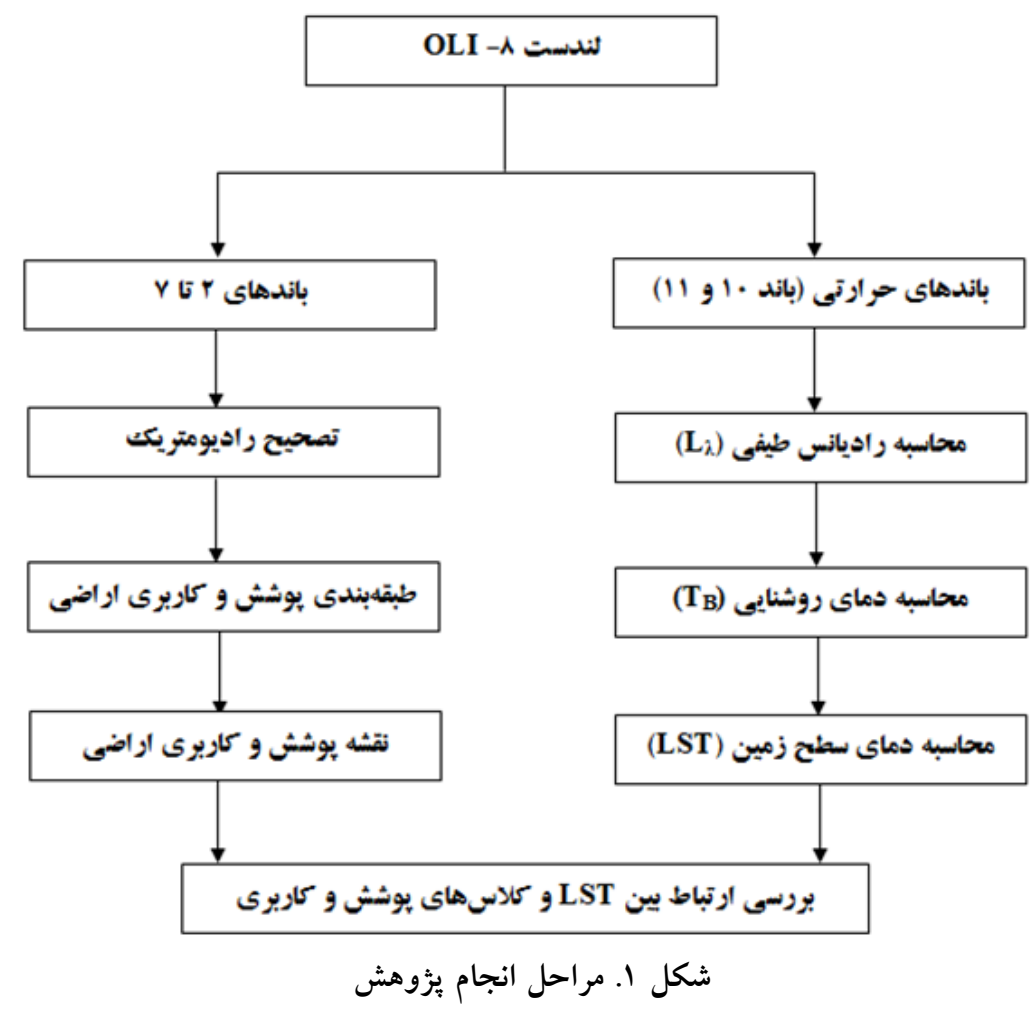

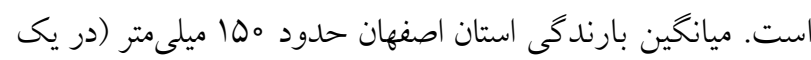
روش ينجره مجزا بهمنظور تهيه نقشه دماى سطح زمين استفاده دوره وب ساله) است (10) - (10). كردهاند.

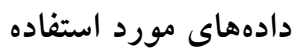

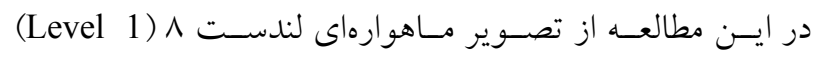

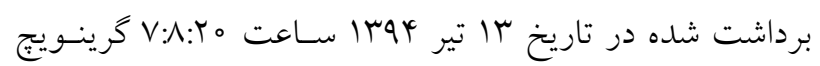

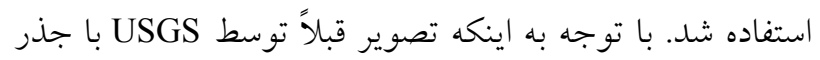

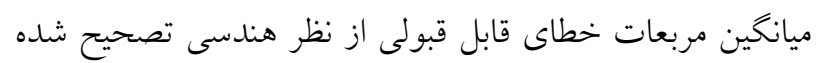

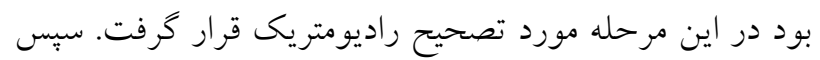

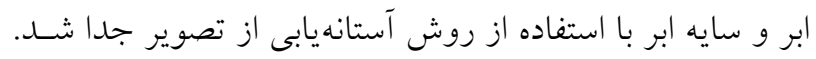
هدف از اين مطالعه بررسى و شناخت الكَى دمايى بخـش

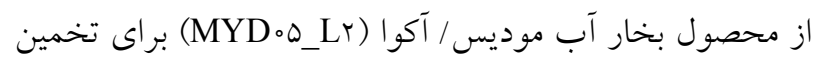
بخار آب موجود در منطقه استفاده شد. منطقه مورد مطالعه

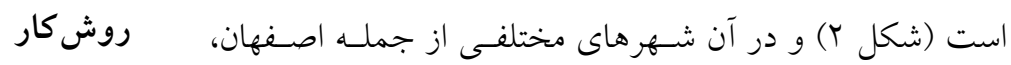
تخمين LST با استفاده از الكوريتم ينجره مجزا الكَوريتم ينجره مجزا كه كامل ترين روش تخمسين LST تـاكنون

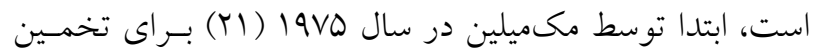

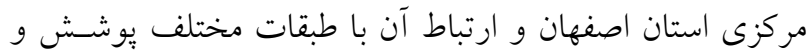
كاربرى اراضى است كه بـدين منظـور نقشـهـ LST از بانـدهاى

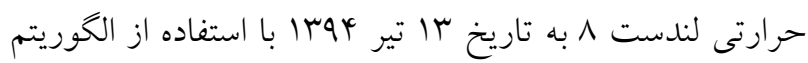

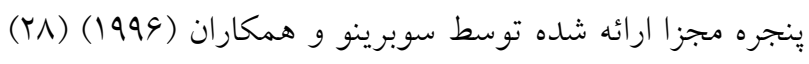

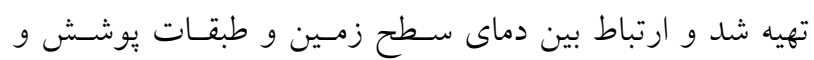

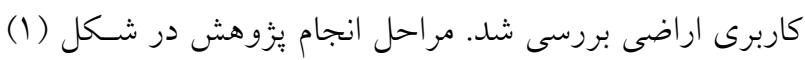

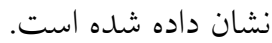
خمينى شهر، نجف آباد، فلاورجان، مباركـه و شـاهينشـهر قـرار

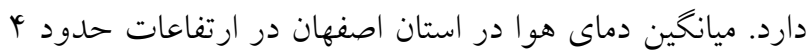

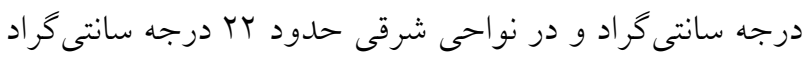



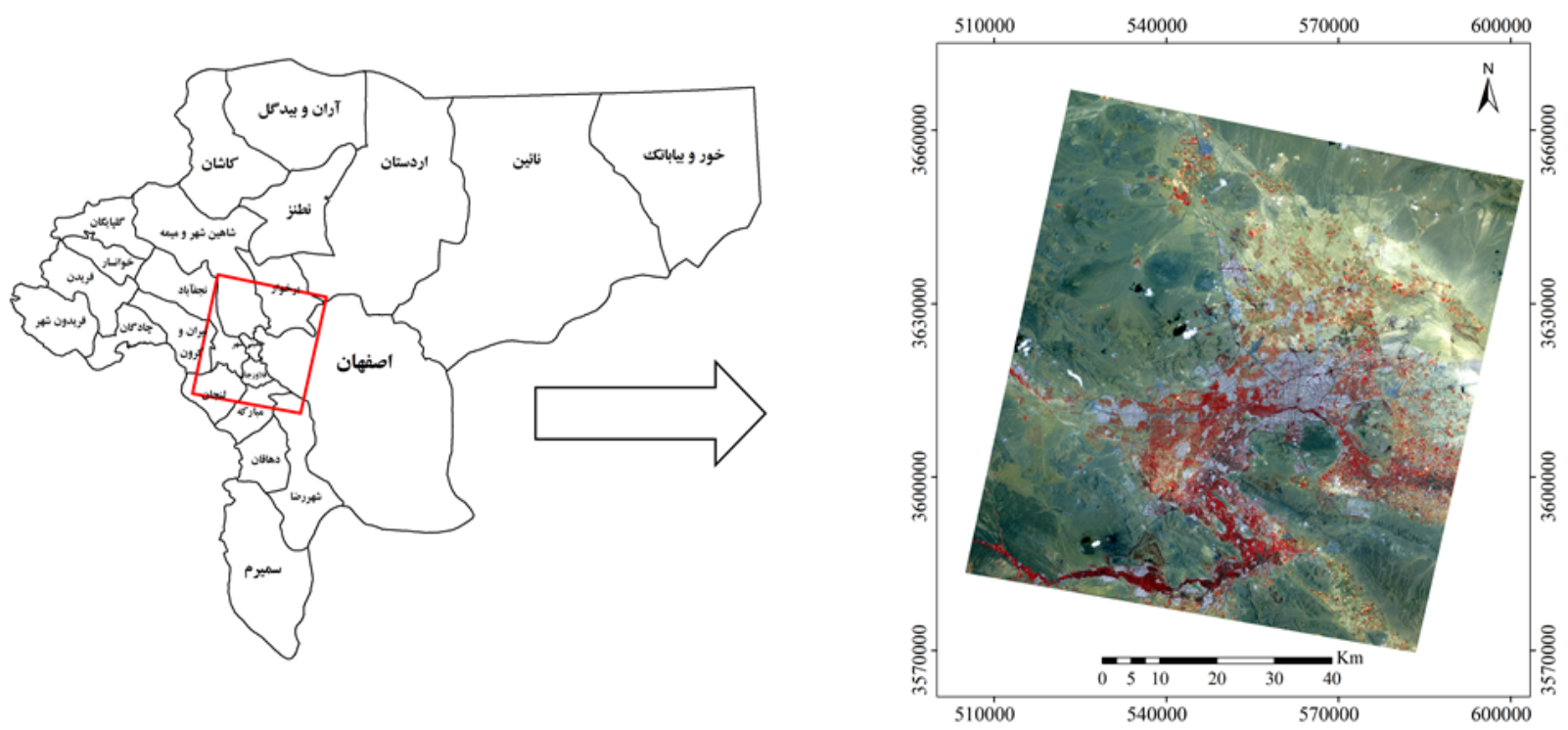

شكل r. منطقه مورد مطالعه

جدول ا. ضرايب مورد استفاده براى روش ينجره مجزا (r)

\begin{tabular}{|c|c|c|c|c|c|c|}
\hline $\mathrm{C}$ 。 & $C_{1}$ & $\mathrm{C}_{\mathrm{r}}$ & $\mathrm{C}_{r}$ & $\mathrm{C}_{4}$ & $\mathrm{C}_{\Delta}$ & $\mathrm{C}_{\varphi}$ \\
\hline$-0 / 49 \Lambda$ & $I / \pi V \Lambda$ & ०/AN & $\Delta \psi / \mu_{0}$ & 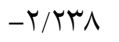 & $-1 Y q / Y_{0}$ & $18 / 4 \circ$ \\
\hline
\end{tabular}

دماى روشـنايى (Brightness temperature) مربسوط Ti به سنجنده در باندهاى ينجره مجزاى i و j (بر حسب كلوين) ع = ميانحين ضريب گسيل: (ci $\Delta \varepsilon=\Delta \varepsilon$ مقدار كل بخار آب اتمسفرى برحسب (كرم بر سانتىمترمربع) W W

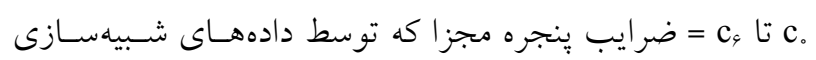
شده تعيين شده است (جدول () (1).

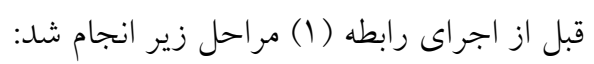

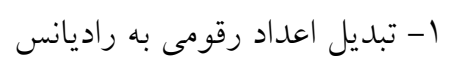

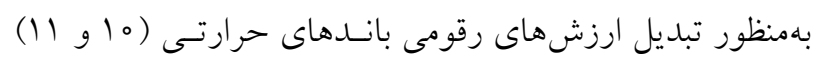
تصوير لندست ^ به راديانس طيفى از رابطـه (r) اسـتفاده شـد

$\mathrm{L}_{\lambda}=\mathrm{M}_{\mathrm{L}} \mathrm{Q}_{\text {cal }}+\mathrm{A}_{\mathrm{L}}$

= L راديانس طيفى دريافـت شــده توسـط سـنجنده برحسبـ

$\left(\mathrm{W} /\left(\mathrm{m}^{r} \mathrm{sr} \mu \mathrm{m}\right)\right)$
دماى سـطح دريـا بــر اسـاس دادههـاى مـادون قرمـز حرارتـى

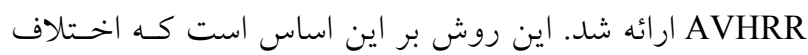

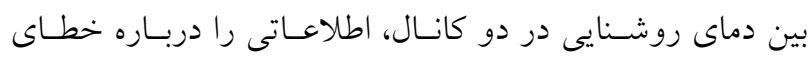

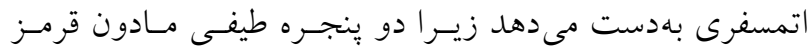
حرارتى از ويزگى هاى جذب متفاوتى برخوردارند. در طول سه دهه كذشته يززوهشخران فرمولبندىهـاى مختلفـى از الخـوريتم ينجره مجزا ارائه كردهاند. فايده اصلى الخوريتم ينجره مجزا ايسن است كه براى شرايط جهان و بنابراين براى محدوده وسـيعى از

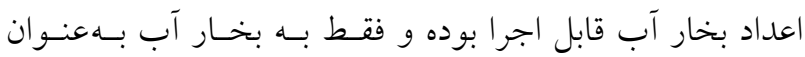
ورودى نياز دارد (بهغير از ضريب گسيل سطح و دو باند مادون

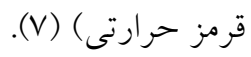
الخوريتم بنجره مجزا ارائه شده در اين مقاله بر اسـاس سـاختار رياضى بيشنهادى توسط سوبرينو و همكاران (YN) است: $\mathrm{T}_{\mathrm{s}}=\mathrm{T}_{\mathrm{i}}+\mathrm{c}_{1}\left(\mathrm{~T}_{\mathrm{i}}-\mathrm{T}_{\mathrm{j}}\right)+\mathrm{c}_{\mathrm{r}}\left(\mathrm{T}_{\mathrm{i}}-\mathrm{T}_{\mathrm{j}}\right)^{\mathrm{r}}+$ 


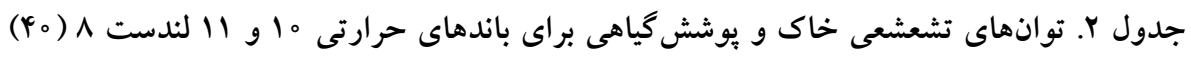

\begin{tabular}{|c|c|c|}
\hline يوشش گياهى & خاى & \\
\hline 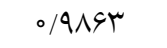 & $0 / 9991$ & باند ه1 \\
\hline $0 / 91999$ & O/QVYF & باند || \\
\hline
\end{tabular}

استفاده شده است (رابطه Y). اين گروه روشهـا براسـاس يـى رابطه آمارى بين NDVI حاصله از بانـدهاى VNIR و LSE در محدودههاى مادون قرمز حرارتى است. اين روش فرض مى كند كه: ا- سطح فقط يوشـيده از خـاك و يوشـش كيـاهى اسـت؛

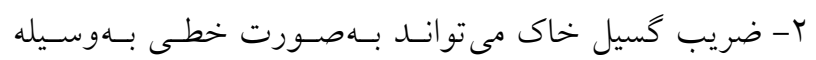
بازتاب سطح در باند قرمز نشان داده شود؛ r- LSE بهصـورت خطى با توجه به نسبت يوشش كيـاهى در يـك بيكسـل تغييـر

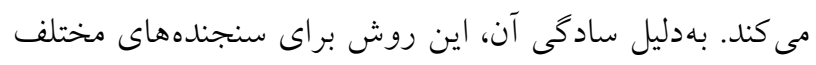
به كار كرفته شده است (1) (1). $\varepsilon=\varepsilon_{\mathrm{V}} \mathrm{P}_{\mathrm{V}}+\varepsilon_{\mathrm{g}}\left(1-\mathrm{P}_{\mathrm{V}}\right)+r<\mathrm{d} \varepsilon>\mathrm{P}_{\mathrm{V}}\left(1-\mathrm{P}_{\mathrm{V}}\right)$

$$
\text { ع = ضريب كسيل }
$$

ع = ضريب گسيل اراضى با بوشش گياهى خالص = $\varepsilon_{g}$

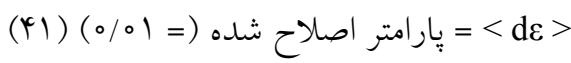
جدول r ضرايب كسيل مـورد اسـتفاده بـراى خــاك و يوشـش كياهى براى باندهاى حرارتى •ا و ال الندست م را نشـان مسى $P_{V}=\left(\frac{N D V I-N D V I}{S}\right)^{r}$

NDVI , NDVI كياهى است (r) (r) (1) براى محاسبه آستانههاى NDVI از اعداد ارائه شده در مقاله مومنى و سرادجيان (YT) كه مربوط به سنجنده مـوديس بـود و در همين منطقه مورد مطالعه اعمال شده بود، استفاده شد. بــين صورت كه ابتدا از رابطه و ضرايب ارائه شده توسـط استيون و

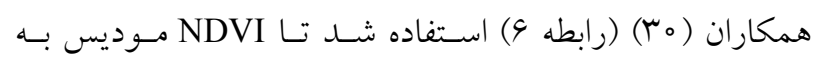
NDVI
= ارزش رقومى بيكسل = Qcal

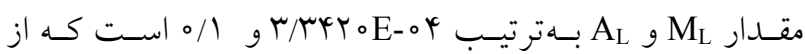
متاديتاى تصوير استخراج شد. T- محاسبه دماى روشنايى (T)

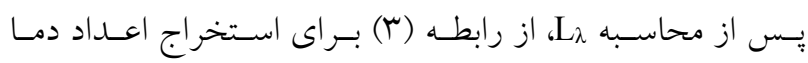
(برحسب كلوين) استفاده شد (سب):

$\mathrm{T}_{\mathrm{B}}=\frac{\mathrm{K}_{r}}{\ln \left(\frac{\mathrm{K}_{1}}{\mathrm{~L}_{\lambda}}+1\right)}$

كه بر طبق متاديتاى تصوير اKنابت كاليبر اسيون براى باند ه ا و

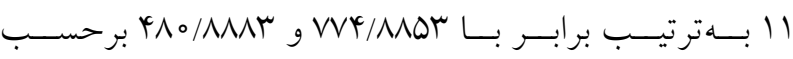

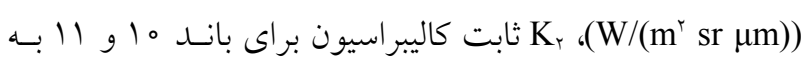

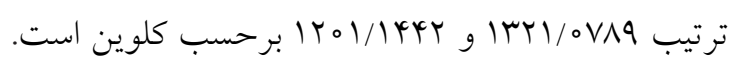
r-محاسبه ضريب گسيل سطح زمين (Land Surface Emissivity) ضريب كسيل سطح (LSE) شاخص كارايى ذاتى سـطح در تبديل انرزى كرمايى به انرزى تابشى بالاى سطح است كـه به تركيب، زبرى و مقدار رطوبت سطح و شـرايط مشـاهده (مانند طول موج، بزرگنمايى بيكسل و زاويه مشاهده) بسـتخى

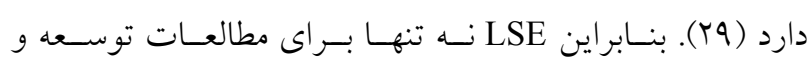
فرسـايش خــاك و تخمسين مقــادير بوشـش كيـاهى بر اكنـده و تغييرات آن، بلكه براى نقشهسازى سنگ بستر و كشف منابع و نيز

براى تخمين دقيق محتواى انرزى سطح حائز اهميت است (19). روش هاى مختلفى براى بهدست آوردن LSE وجــود دارد.

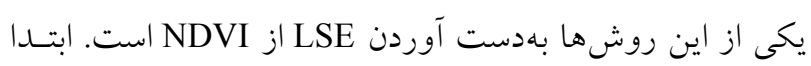

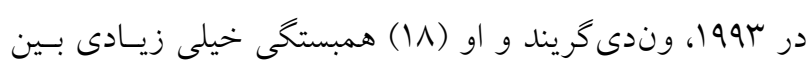
در بانـدهاى مـادون قرمـز حرارتـى در محسدوده بـ LSE

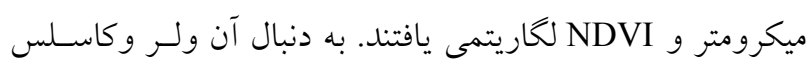

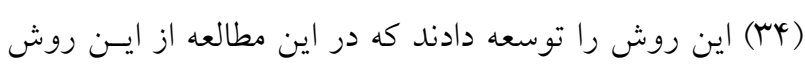


جدول r. آستانهاى استفاده شده براى NDVI در اين بئوهش

\begin{tabular}{|c|c|c|}
\hline \multicolumn{2}{|c|}{ آستانه } & \multirow{2}{*}{ تصوير ماهوارهاى } \\
\hline خاك نسبتاً يوشيده شده با كياه & خاك باير & \\
\hline$\circ / 109 \leq \mathrm{NDVI} \leq 0 / 491$ & $\mathrm{NDVI}<0 / 109$ & (Yr) MODIS \\
\hline$\circ / / 4 \varphi \leq \mathrm{NDVI} \leq \circ / 4 \Delta \wedge$ & $\mathrm{NDVI}<0 / 149$ & Landsat-v ETM+ \\
\hline $0 / N \psi r \leq \mathrm{NDVI} \leq \circ / 4 q \mu$ & $\mathrm{NDVI}<\circ / / 4 \mathrm{r}$ & Landsat-^ OLI \\
\hline
\end{tabular}
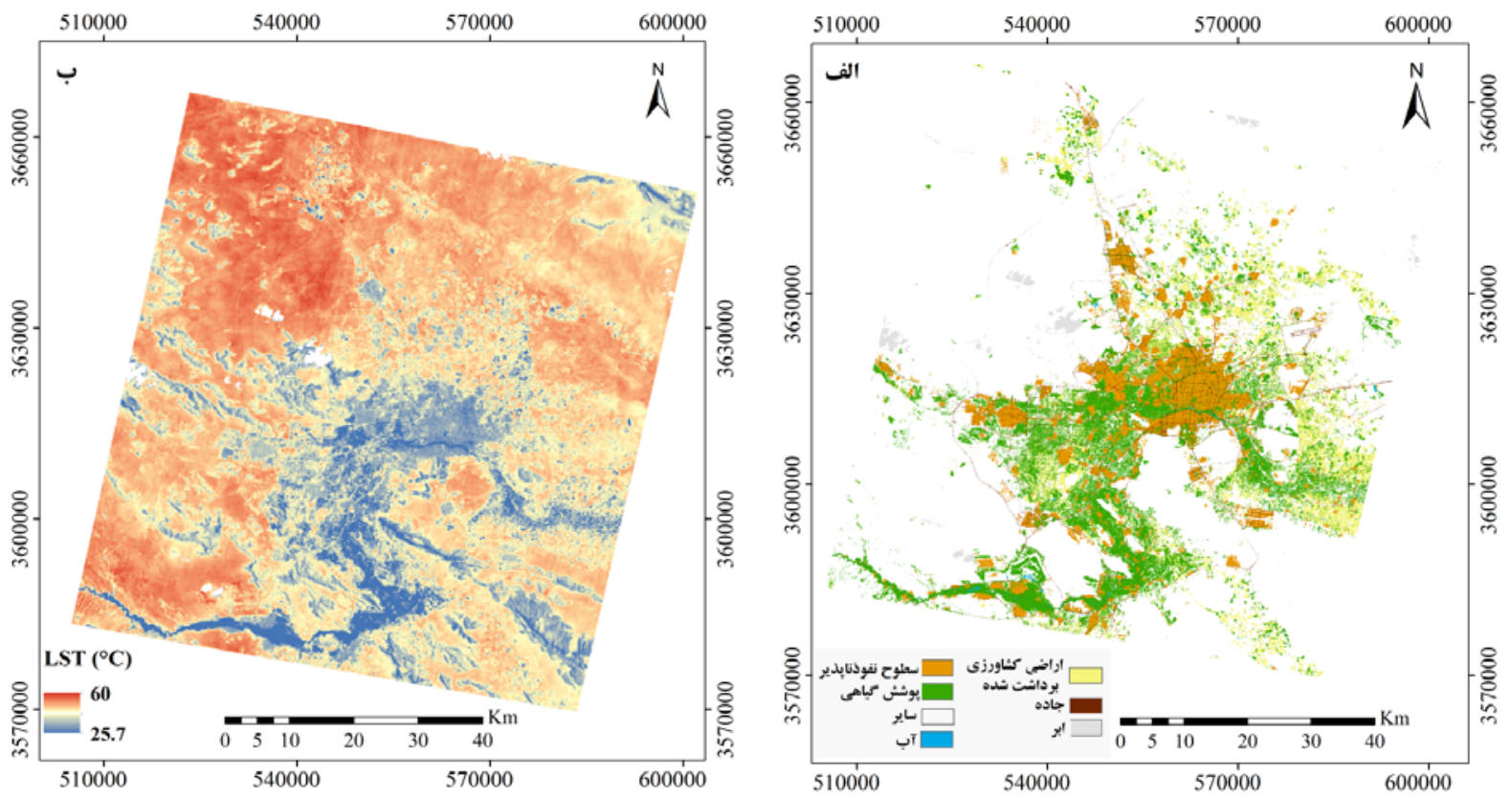

شكل r. الف) نقشه يوشش و كاربرى اراضى و ب) توزيع مكانى LST بخش مركزى استان اصفهان

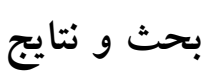

بهمنظور تهيه نقشه يوشش و كاربرى اراضسى از طبقـهبنــى بـهـ

روش ماشـين بــردار يشـتيبان (Support Vector Machine) استفاده شد. نقشـه يوشـش و كـاربرى اراضسى در شـش طبقـهـ سـطوح نفوذنايــذير، جـاده، بوشـش گيـاهى (شـامل اراضـى كشاورزى، كلخانهها، فضـاى سـبز و بوشـش گيـاهى طبيعى)، اراضى كشاورزى برداشت شـده، سـاير اراضسى (شـامل خـاك،

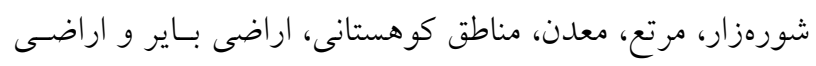
كشت نشده در زمان مورد بررسىى) و آب بـا صسحت كلى ترصد توليد شد (شكل r- الف). جدول (Y) مسـاحت طبقـات نقشه يوشش و كاربرى را نشان مىدهد.
بهدست آمله براى ETM+ و رابطـهـ ارائـهـ شـده توسـط كى و

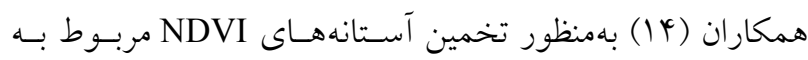

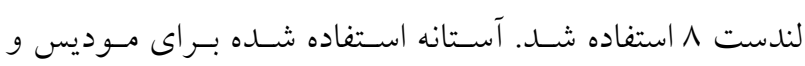

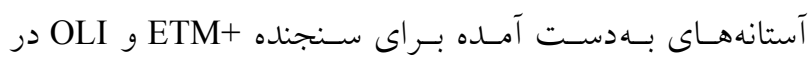
جدول (r) آورده شده است. باست $\mathrm{NDVI}_{\text {reference }}=\mathrm{a}+\mathrm{b} \cdot \mathrm{NDVI}_{\text {measured }}$

Y - تخمين مقدار بخار آب بهمنظور بهدست آوردن بخار آب، از محصول بخار آب موديس/ آكوا كه با استفاده از الخوريتم مادون قرمز نزديك بـا (MYD。D_Lr) قدرت تفكيك مكانى يك كيلومتر در همـان روز سـاعت UTC •ه:9 برداشت شده بود، استفاده شد. 
جدول fا. مساحت طبقات مختلف نقشه يوشش و كاربرى اراضى برحسب كيلومتر مربع

\begin{tabular}{|c|c|c|c|c|c|c|}
\hline ابر & آب & ساير & برداضى كشاورزى & يو شياهى & سطوح نقودنايذير & كالس هاى يوشش و \\
\hline$r \Delta / N$ & $9 / 19$ & $019 \wedge / Y \wedge$ & rVI/NI & $V 11 / 9 r$ & $490 / 09$ & مساحت \\
\hline
\end{tabular}

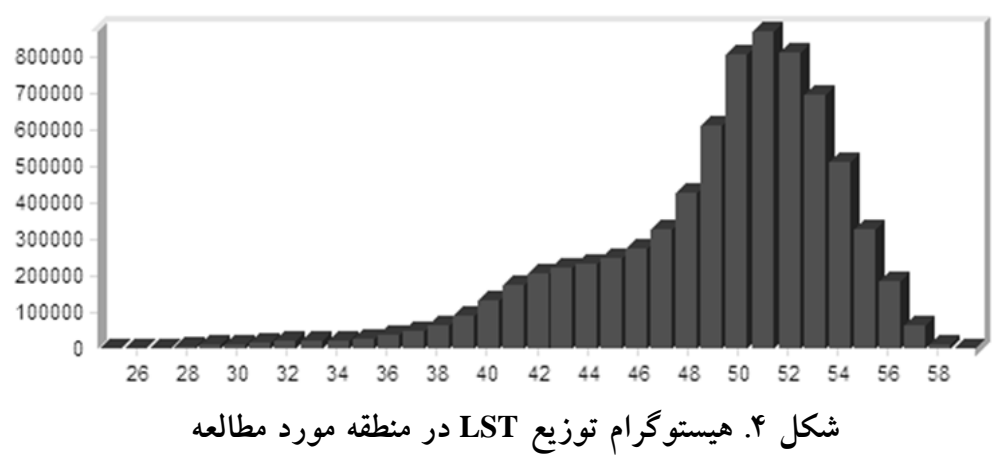

مطالعه كه دربر گيرنده مناطق مسكونى، جادهها و صـنايع اسـت، جزء نقاط داغ محسوب مىشوند. مطالعات نشان مسىدهنــ كـه كسترش شهرى و فعاليـتهــاى انسـانى منجــر بــه تغييراتى در

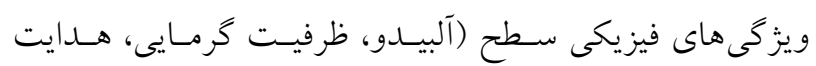

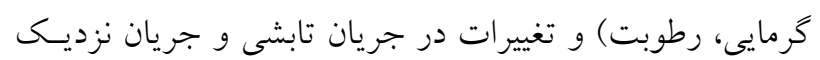

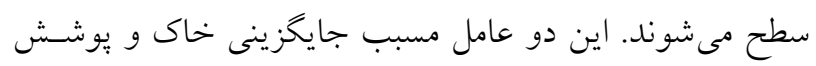

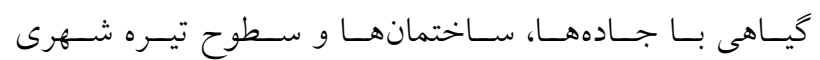

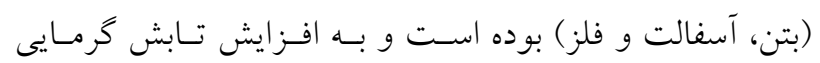

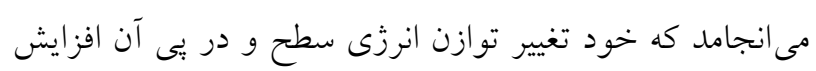

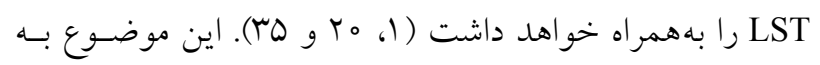
افزايش جريان محسوس گرمايى و در نهايت افزايش دماى هـوا

$$
\text { منجر مىشود (ب). (ب). }
$$

كمترين دماى سطح در اين منطقه مربوط به محيطهاى آبسى از جمله رودخانه زاينـدهرود، اسـتخرها و حوضسجهه هــاى آبسى

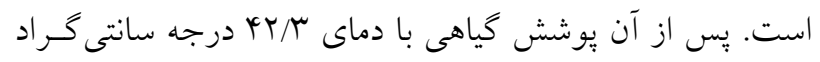
دماى سطح كمترى را نشان داده است. مطالعـات نشـان دادهانـد كه مناطق سبز داراى نسبت بوون متفاوتى نسبت به سطح باير و معدنى هستند زيرا تابش خورشيدى وارده به انرزى براى تعـرق و فتوسنتز توسط كياهان تبديل شده و جريان خرماى محسـوس

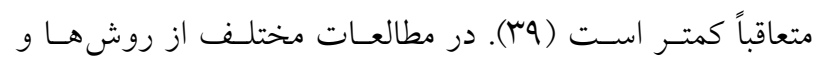

نقشـه LST محاسـبه شـده از بانسدهاى حرارتسى لندسـت ^ بـا استفاده از روش يُجره مجزا در شكل (r- ب) نشان داده شــه

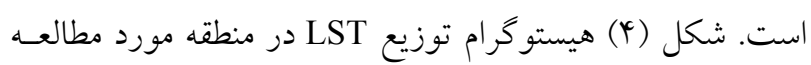

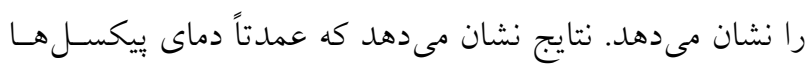

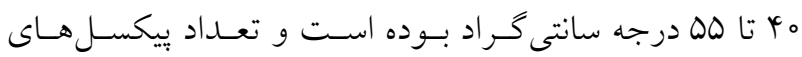

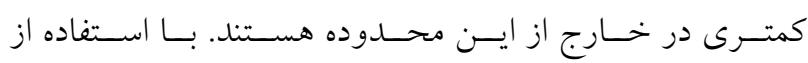

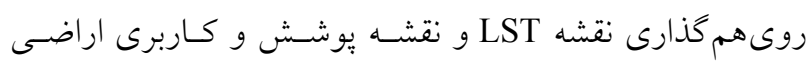

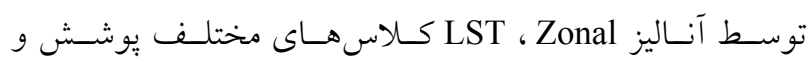

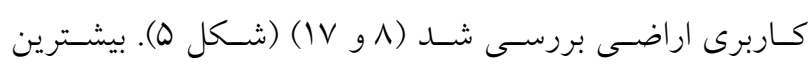
وسعت يوشش اراضى در منطقه مورد مطالعه مربوط بــه كـلاس

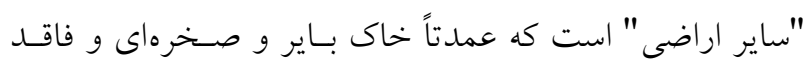
يوشش گياهى متراكم بوده و بيشترين دماى سـطح يعنى هo/9 درجه سانتى كراد را به خود اختصاص داده است كه عدم تبخيـر و تعرق و وجود سايه مىتواند از دلايل بيشتر بودن دمـاى ايسن كلاس نسبت به بقيه كلاس ها باشد. يسـ از آن كـلاس اراضسى

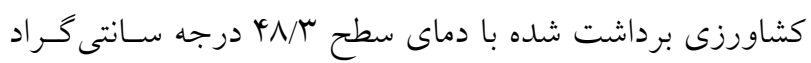

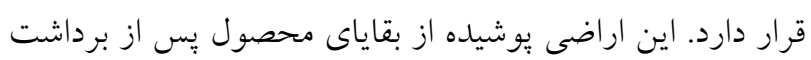

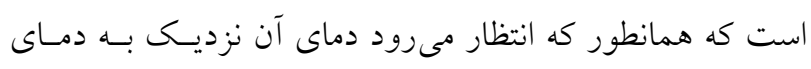
خاك است. سيس سطوح نفوذنايذير با دمـاى سـطح هأ درجـه. سانتى گراد قرار دارد. سطوح نفوذنايذير موجود در منطقه مـورد 


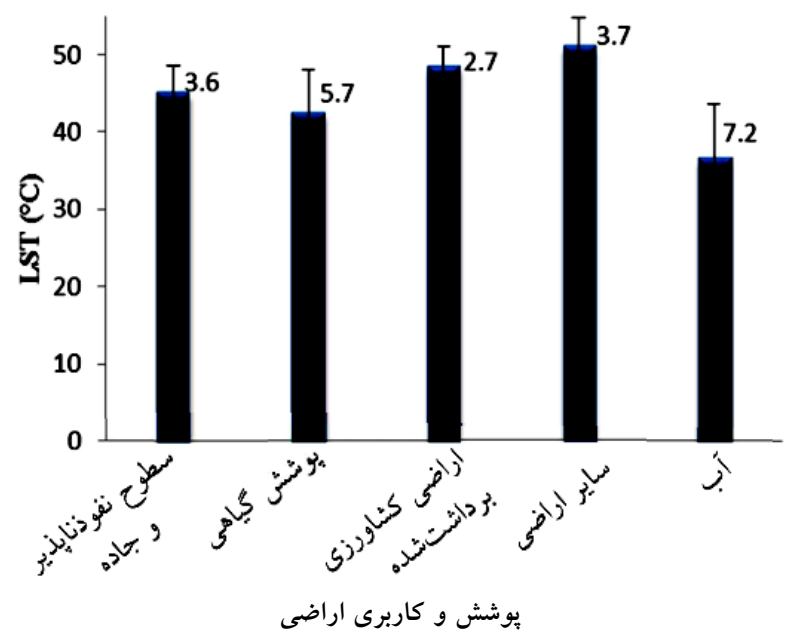

شكل ه. ميانكين LST انواع يوشش و كاربرى اراضى در منطقه مورد مطالعه (انحر اف معيار LST طبقات در كنار ستوذها ذكر شده است)

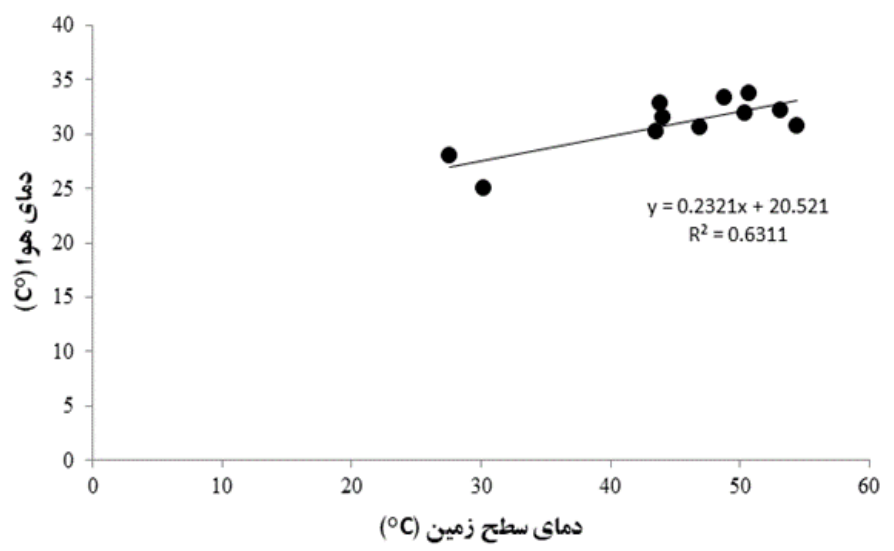

شكل 9. ارتباط بين دماى هوا و دماى سطح زمين (LST)

بررسى كرد. بدين ترتيـب از دمـاى هـواى ايستخاههـاى شـرق

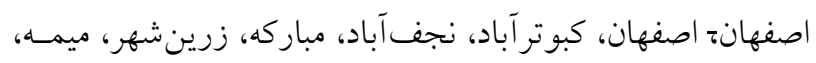

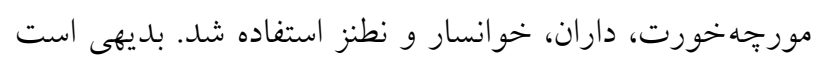

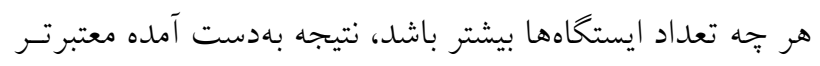

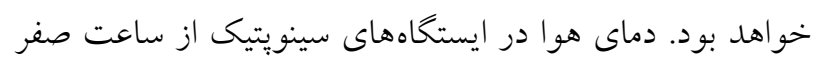

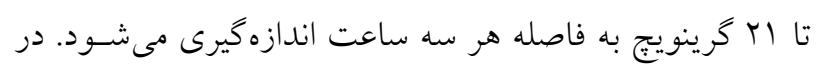

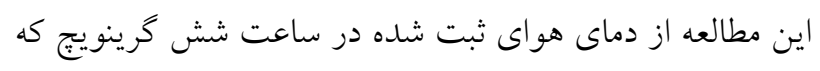

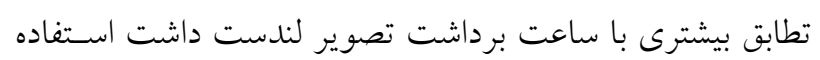

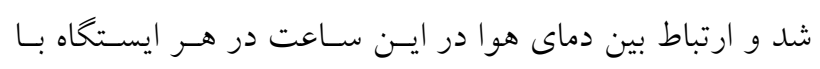

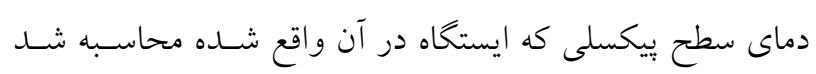

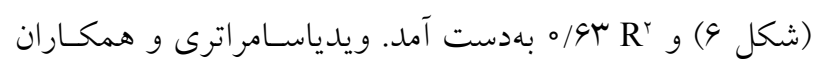

سنجندهاى متفاوتى براى محاسبه LST بهره كرفتهاند از جملـه

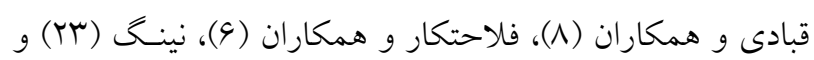

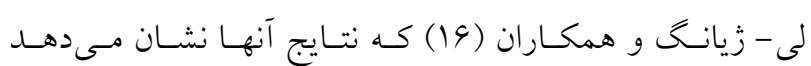

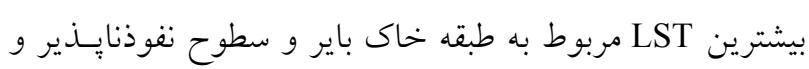

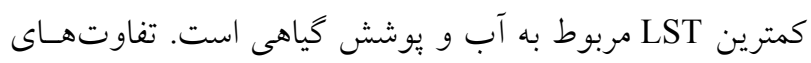

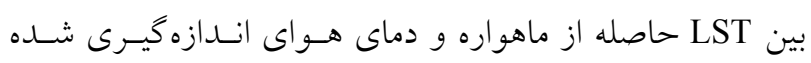

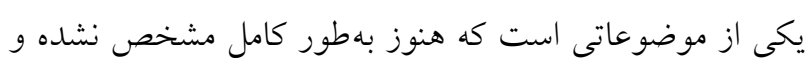

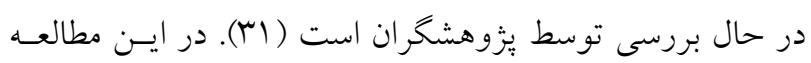

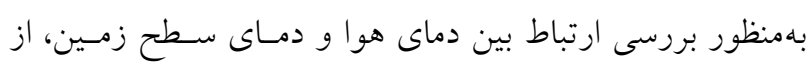

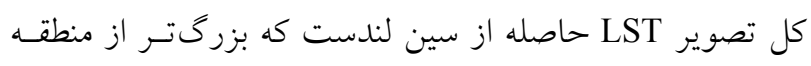

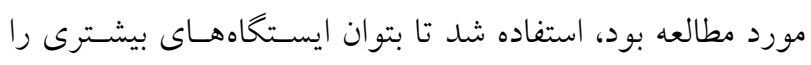




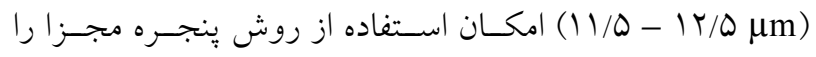

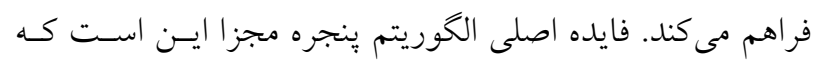

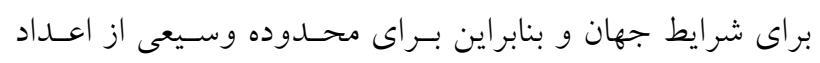

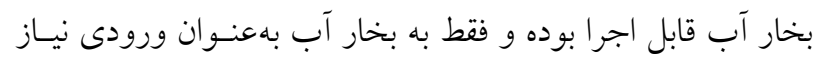

$$
\begin{aligned}
& \text { دارد (بهغير از ضريب كسيل سطح و دو باند مادون قرمز حرارتى). }
\end{aligned}
$$

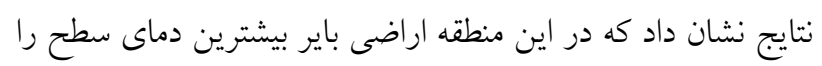

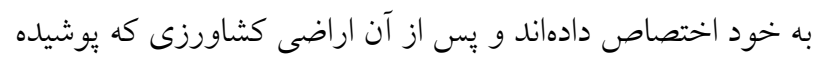

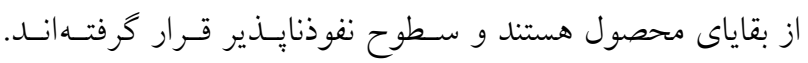

$$
\begin{aligned}
& \text { كمترين LST به محيطهاى آبى و يوشش كياهى تعلق داشت. } \\
& \text { سباسگز ارى } \\
& \text { اين مطالعه با حمايت دانشخاه صنعتى اصفهان انجام شده اسـت. } \\
& \text { همجنين از اداره هواشناسى شهر اصفهان بهخاطر در اختيار قرار } \\
& \text { دادن دادههاى هواشناسى قدردانى مىشود. }
\end{aligned}
$$

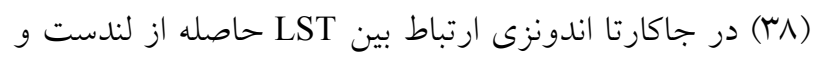

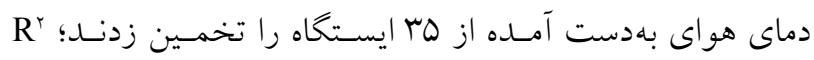

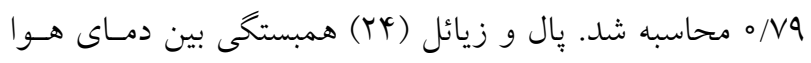

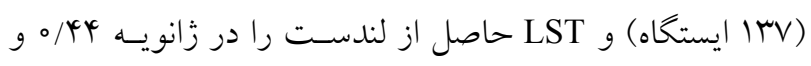

$$
\begin{aligned}
& \text { در آوريل 90/ كزارش كردند. } \\
& \text { نتيجه گيرى } \\
& \text { دماى سطح زمين (LST) داراى كاربردهاى زيادى در زمينه هاى }
\end{aligned}
$$

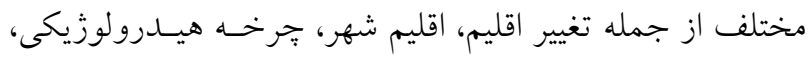

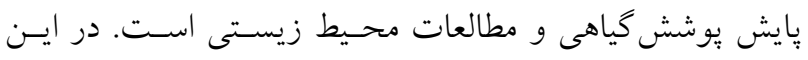

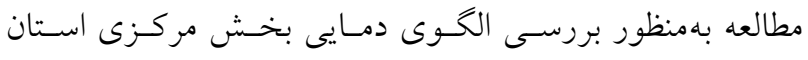

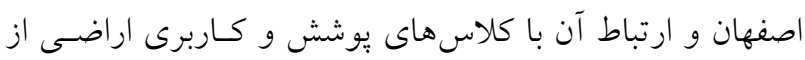

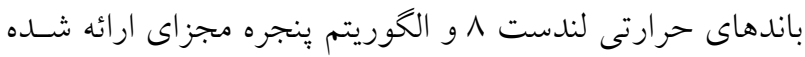

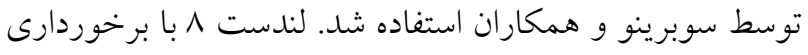

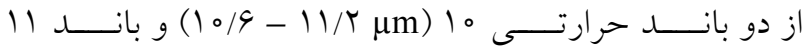

منابع مورد استفاده

1. Basar, U. G., S. Kaya and M. Karaca. 2008. Evaluation of urban heat island in Istanbul using remote sensing techniques. The International Archive of Photogrammetry, Remote Sensing and Special Information Science 36: 971-976.

2. Benali, A., A. C. Carvalho, J. P. Nunes, N. Carvalhais and A. Santos. 2012. Estimating air surface temperature in Portugal using MODIS LST data. Remote Senseng of Environment 124: 108-121.

3. Carlson, T. N. and D. A. Ripley. 1997. On the relation between NDVI, fractional vegetation cover, and leaf area index. Remote Senseng of Environment 62: 241-252.

4. Cristóbal, J., J. C. Jiménez-Muñoz, J. A. Sobrino, M. Ninyerola and X. Pons. 2009. Improvements in land surface temperature retrieval from the Landsat series thermal band using water vapor and air temperature. Journal of Geophysical Research Atmospheres 114.

5. Czajkowski, K. P., S. N. Goward, S. Stadler and A. Walz. 2000. Thermal remote sensing of near surface environmental variables: application over the Oklahoma Mesonet. The Professional Geographer 52: 345-357.

6. Falahatkar, S., S. M. Hosseini and A. R. Soffianian. 2011. The relationship between land cover changes and spatialtemporal dynamics of land surface temperature. Indian Journal of Science and Technology 4: 76-81.

7. GCOS. 2011. Supplemental details to the satellite-based component of the "implementation plan for the global observing system for climate in support of the UNFCCC.

8. Ghobadi, Y., B. Pradhan, H. Z. M. Shafri and K. Kabiri. 2015. Assessment of spatial relationship between land surface temperature and landuse/cover retrieval from multi-temporal remote sensing data in South Karkheh Sub-basin, Iran. Arabian Journal of Geoscience 8: 525-537.

9. Jiménez-Muñoz, J. C., J. Cristóbal, J. A. Sobrino, G. Sòria, M. Ninyerola and X. Pons. 2009. Revision of the singlechannel algorithm for land surface temperature retrieval from Landsat thermal-infrared data. IEEE Transactions on Geoscience and Remote Sensensing 47: 339-349.

10. Jiménez-Muñoz, J. C. and J. A. Sobrino. 2003. A generalized single-channel method for retrieving land surface temperature from remote sensing data. Journal of Geophysical Research: Atmospheres 108.

11. Jiménez-Muñoz, J. C. and J. A. Sobrino. 2008. Split-Window coefficients for land surface temperature retrieval from low-resolution thermal infrared sensors. IEEE Geoscience and Remote Sensing Letters 5: 806-809. 
12. Jiménez-Muñoz, J. C. and J. A. Sobrino. 2010. A single-channel algorithm for land-surface temperature retrieval from ASTER data. IEEE Geoscience and Remote Sensing Letters.7: 176-179.

13. Jiménez-Muñoz, J. C., J. A. Sobrino, D. Skokovic, C. Mattar and J. Cristóbal. 2014. Land surface temperature retrieval methods from Landsat-8 Thermal Infrared Sensor data. IEEE Transactions on Geoscience and Remote Sensing 1840-1843.

14. Ke, Y., J. IM, J. Lee, H. Gong and Y. Ryu. 2015. Characteristics of Landsat 8 OLI-derived NDVI by comparison with multiple satellite sensors and in-situ observations. Remote Sensing of Environment 164: 298-313.

15. Khodagholi, M., R. Saboohi and Z. Eskandari. 2014. Analysing drought past trend and forecasting its future in Isfahan province. Journal of Water and Soil Science 18: 367-379.

16. Le-Xiang, Q., C. Hai-Shan and C. Jie. 2006. Impacts of land use and cover change on land surface temperature in the Zhujiang Delta. Pedosphere 16: 681-689.

17. Li, J., C. Song, L. Cao, F. Zhu, X. Meng and J. Wu. 2011. Impacts of landscape structure on surface urban heat islands: A case study of Shanghai, China. Remote Sensing of Environment 115: 3249-3263.

18. Li, Z. L., B. Tang, H. Wu, H. Ren, G. Yan, Z. Wan, I. F. Trigo and J. A. Sobrino. 2013. Satellite-derived land surface temperature: Current status and perspectives. Remote Sensensing of Environment 131: 14-37.

19. Li, Z.-L., H. Wu, N. Wang, S. Qiu, J. A. Sobrino, Z. Wan, B. Tang and G. Yan. 2013. Land surface emissivity retrieval from satellite data: review article. International Journal of Remote Sensing 1-44.

20. Lo, C. P. and D. A. Quattrochi. 2003. Land-use and land-cover change, urban heat island phenomenon, and health implications: a remote sensing approach. Photogrammetric Engeeniering and Remote Sensing 69: 1053-1063.

21. McMillin, L. M. 1975. Estimation of sea surface temperature from two infrared window measurements with different absorptions. Journal of Geophysical Research 80: 5113-5117.

22. Momeni, M. and M. R. Saradjian. 2007. Evaluating NDVI-based emissivities of MODIS bands 31 and 32 using emissivities derived by Day/Night LST algorithm. Remote Sensing of Environment 106: 190-198.

23. Ning, J. 2011. Influence of coastal land use change to land surface temperature. Energy Procedia 11: 3999-4004.

24. Pal, S. and S. Ziaul. 2017. Detection of land use and land cover change and land surface temperature in English Bazar urban centre. The Egyptian Journal of Remote Sensing and Space Sciences 20: 125-145.

25. Qin, Z., A. Karnieli and P. Berliner. 2001. A mono-window algorithm for retrieving land surface temperature from Landsat TM data and its application to the Israel-Egypt border region. International Journal of Remote Sensing 22: 3719-3746.

26. Quattrochi, D. A. and J. C. Luvall. 2004. Thermal Remote Sensing in Land Surface Processes. FL: CRC Press, Boca Raton.

27. Sobrino, J. A. and J. C. Jiménez-Muñoz. 2005. Land surface temperature retrieval from thermal infrared data: an assessment in the context of the Surface Processes and Ecosystem Changes through Response Analysis (SPECTRA) mission. Journal of Geophysical Research: Atmospheres 110: 1-10.

28. Sobrino, J. A., Z. L. Li, M. P. Stoll and F. Becker. 1996. Multi-channel and multi-angle algorithms for estimating sea and land surface temperature with ATSR data. International Journal of Remote Sensing 17: 2089-2114.

29. Sobrino, J. A., N. Raissouni and Z. L. Li. 2001. A comparative study of land surface emissivity retrieval from NOAA data. Remote Sensing of Environment 75: 256-266.

30. Steven, M. D., T. J. Malthus, F. Baret, H. Xu and M. J. Chopping. 2003. Intercalibration of vegetation indices from different sensor systems. Remote Sensing of Environment 88: 412-422.

31. Tomlinson, C. J., L. Chapman, J. E. Thornesb and C. Baker. 2011. Remote sensing land surface temperature for meteorology and climatology: a review. Meteorological Application 18: 296-306.

32. Urban, M., J. Eberle, C. Hüttich, C. Schmullius and M. Herold. 2013. Comparison of satellite-derived land surface temperature and air temperature from meteorological stations on the Pan-Arctic scale. Remote Sensing of Environment 5: 2348-2367.

33. USGS. https://landsat.usgs.gov/landsat-8.

34. Valor, E. and V. Caselles. 1996. Mapping land surface emissivity from NDVI: application to European, African and South American areas. Remote Sensing of Environment 57: 167-184.

35. Voogt, J. 2002. Urban Heat Island. Wiley, New York,

36. Wang, K., J. Wang, P. Wang, M. Sparrow, J. Yang and H. Chen. 2007. Influences of urbanization on surface characteristics as derived from the moderate-resolution imaging spectroradiometer: a case study for the Beijing metropolitan area. Journal of Geographical Research: Atmospheres 112: 1-12.

37. Wang, S., L. He and W. Hu. 2015. A temperature and emissivity separation algorithm for Landsat-8 thermal infrared sensor data. Remote Sensing of Environment 7: 9904-9927.

38. Widyasamratri, H., K. Souma, T. Suetsugi, H. Ishidaira, Y. Ichikawa, H. Kobayashi and I. Inagaki. 2013. Air Temperature Estimation from Satellite Remote Sensing to Detect the Effect of Urbanization in Jakarta, Indonesia. Journal of Emerging Trends in Engineering and Applied Sciences (JETEAS) 4: 800-805. 
39. Wong, N. H. and C. Yu. 2005. Study of green areas and urban heat island in a tropical city. Habitat International 29: 547-558.

40. Yu, X., X. Guo and Z. Wu. 2014. Land surface temperature retrieval from Landsat 8 TIRS-comparison between Radiative Transfer Equation-Based method, Split Window algorithm and Single Channel method. Remote Sensing of Environment. 6: 9829-9852.

41. Zhang, J., Y. Wang and Y. Li. 2006. A C++ program for retrieving land surface temperature from the data of Landsat TM/ETM+ band 6. Computer and Geosciences 32: 1796-1805. 


\title{
Estimating Land Surface Temperature in the Central Part of Isfahan Province Based on Landsat-8 Data Using Split- Window Algorithm
}

\author{
M. Madanian ${ }^{1 *}$, A. R. Soffianian ${ }^{1}$, S. Soltani Koupai ${ }^{2}$, S. Pourmanafi ${ }^{1}$ and M. Momeni ${ }^{3}$
}

(Received: April 10-2017 ; Accepted: September 24-2017)

\begin{abstract}
Land surface temperature (LST) is used as one of the key sources to study land surface processes such as evapotranspiration, development of indexes, air temperature modeling and climate change. Remote sensing data offer the possibility of estimating LST all over the world with high temporal and spatial resolution. Landsat-8, which has two thermal infrared channels, provides an opportunity for the retrieval of LST using the split- window method. The main objective of this research was to analyze the LST of land use/land cover types of the central part of Isfahan Province using the split- window algorithm. The obtained results demonstrated that the "other" class which had been mainly covered with bare lands exhibited the highest LST $\left(50.9^{\circ} \mathrm{C}\right)$. Impervious surfaces including residential areas, roads and industries had the LST of $45^{\circ} \mathrm{C}$. The lowest temperature was observed in the "water" class, which was followed by vegetation. Vegetation recorded a mean LST of $42.3^{\circ} \mathrm{C} . \mathrm{R}^{2}$ was 0.63 when regression was carried out on LST and air temperature.
\end{abstract}

Keywords: Land surface temperature, Split-window algorithm, Landsat-8, Central part of Isfahan Province

1. Department of Environmental Sciences, Faculty of Natural Resources, Isfahan University of Technology, Isfahan, Iran..

2. Department of Range and Watershed Management, Faculty of Natural Resources, Isfahan University of Technology, Isfahan, Iran.

3. Remote Sensing Division, Department of Geomatics Engineering, University of Isfahan, Iran.

*: Corresponding author: madanian.ma@yahoo.com 